\title{
Debate
}

\section{LOS DIEZMOS EN COLOMBIA Y ECUADOR: un dilema para el estado, un sustento para la Iglesia.}

\author{
Mary Candelo Ramírez ${ }^{* *}$
}

\begin{abstract}
Resumen:
Los diezmos en Colombia y Ecuador, suscitaron conflictos por su eliminación o vigencia en tanto obstáculos para el desarrollo de la agricultura y su vinculación a la economía mundial. El análisis sobre su distribución y los mecanismos de cobro, permiten un primer acercamiento a los diversos problemas que se generaron a su alrededor.
\end{abstract}

Palabras clave: Diezmo, Iglesia, Estado

\begin{abstract}
The tithes in Colombia and Ecuador, raised conflicts for their elimination or validity as long as obstacles for the development of the agriculture and their linking to the world economy. The analysis on their distribution and the collection mechanisms, they allow a first approach to the diverse problems that were generated around to its.
\end{abstract}

Key words: Tithe, Church, state

\footnotetext{
*Artículo de Investigación Científica tipo 2: de Reflexión, según clasificación de COLCIENCIAS. Presenta resultados de investigación de la tesis de maestría: "IGLESIA-ESTADO EN COLOMBIA Y ECUADOR 1830-1860", Universidad Andina Simón Bolívar. Fecha de recepción: 09/04/06

Aceptado para su publicación: 18/05/06
} 


\section{Introducción}

Los temas en torno a las relaciones Iglesia y Estado han sido muy debatidos en la historiografía Latinoamericana, dada su importancia en la construcción de la nación durante el siglo XIX. En regiones como Colombia y Ecuador, objetos de nuestro análisis, existen trabajos dedicados al estudio de estas relaciones. Unos caracterizados por su visión apologética y tradicionalista y otros tratando de relativizar esta visión aportando elementos de análisis que permitan obtener otra lectura de esta realidad.

El objetivo de este artículo es centrarse en la relación Estado - Iglesia, a partir de la supresión del diezmo como impuesto, que llegó a convertirse en un obstáculo para el desarrollo de la agricultura y la economía nacional. Aproximándose a un estudio comparativo entre Colombia y Ecuador, como ejemplos significativos a estudiar. En primer lugar, por ser parte del área andina y haber compartido hasta cierto momento sus historias en lo que fue la Gran Colombia. En segundo lugar, por el papel importante que cumplieron sus respectivas iglesias y estados en la construcción de la nación.

${ }^{\circ}$ El presente artículo se divide en tres partes: la primera tiene como objetivo describir brevemente como funcionaban los diezmos en la colonia y primeras décadas de la república. La segunda explica cómo se distribuían los diezmos y cuáles fueron los mecanismos de cobro. La última parte presenta los conflictos que se dieron por la supresión o vigencia de éstos.

\footnotetext{
***ofesora contratista Departamento de Historia, Universidad del Valle. Magíster en Estudios Latinoamericanos con mención en Historia Andina. Universidad Andina Simón Bolívar, Quito - Ecuador. Miembro del grupo de investigación REGIÓN, Departamento de Historia, Facultad de Humanidades, Universidad del Valle. candelo5@yahoo.com/
} 


\section{Desarrollo}

\section{Los diezmos en la colonia}

Los diezmos encuentran sus antecedentes en la colonia. El Papa Alejandro VI concedió al Rey de España el privilegio especial de manejar los diezmos desde los primeros días de la conquista de América. Sistema que luego fue heredado por los estados independientes de América Latina.

El diezmo consiste en el cobro del diez por ciento de los productos agrícolas y pecuarios, no afectaba a otros de origen manufacturero y bancario. ${ }^{1}$ Este impuesto era cobrado por el estado para el sostenimiento de la iglesia, cobijaba únicamente a agricultores y ganaderos. ${ }^{2}$

Este impuesto, no comprometía al conjunto de la producción existente en el agro. Todo dependía de los productos dominantes o de mayor comercialización en el ámbito parroquial o regional. En muchos casos para estimular la producción de ciertos productos de exportación, se estableció la exoneración de este cobro, como aconteció con el cacao, el tabaco, añil y algodón, en la década del veinte en Ecuador $^{3}$ y en Colombia en los 30, también se dio una especie de extinción gradual del diezmo por medio de la exención de

\footnotetext{
${ }^{1}$ Al respecto ver: Fuente Alba Gerardo. "La sociedad indígena en las primeras décadas de la república: continuidades coloniales y cambios republicanos", En: Nueva Historia del Ecuador, Vol. 8. Época Republicana II, Perspectiva General del siglo XIX. Quito: Corporación Editora Nacional, 1996, pp. 56-57; Gonzalo Ortiz. "Panorama histórico del período 1875-1895", En: Nueva Historia del Ecuador, Vol. 7, Época Republicana y el Ecuador: 1830-1895, Quito: Corporación Editora Nacional, 1994, pp. 258

${ }^{2}$ Villegas, Jorge. Colombia: enfrentamiento Iglesia-Estado 1819-1887. Bogotá: Editorial la Carreta, 1981, p. 45
} 
este impuesto a los cultivos nuevos de productos comerciables como el algodón, el cacao, el café y el añil. Esta medida fue una concesión a los sectores de economía privada, interesados en indagar las posibilidades que ofrecía el comercio exterior.

\section{Distribución y mecanismos de cobro}

La distribución de los diezmos en la colonia se realizaba de la siguiente manera de acuerdo a las concesiones hechas por la Iglesia a la Corona:

\footnotetext{
.........En primer lugar se tomaba la novena parte de la mitad del total, para enviar á la Caja de Consolidación. En segundo lugar, se tomaban las casas excusadas, para la fábrica de la Catedral. De lo restante, se tomaba la mitad y se distribuían entre el Obispo y el Cabildo, por iguales partes. El resto se dividía en novenas partes, así: dos para el fisco, tres para la fábrica de la Catedral, y las cuatro restantes para pagar los curas que la erección mandase, y el sobrante se acumulaba á la cuarta del Cabildo. Esto era en las diócesis donde los diezmos alcanzaban á cubrir todas las necesidades del culto y sus ministros; porque en las otras el Gobierno recaudaba por su cuenta diezmos y sostenía á sus expensas el culto y sus ministros. ${ }^{4}$
}

Estas fueron las disposiciones que debían observarse en la repartición de los diezmos en la época colonial, pero en la realidad los diezmos se distribuían de otra manera; tres novenos para la Real Hacienda, y el resto se tratabá entre el clero, las iglesias y los hospitales, la administración de estos se hacía entre la jurisdicción civil y eclesiástica. ${ }^{5}$

\footnotetext{
${ }^{3}$ Gaceta de Colombia 137 (1824)

${ }^{4}$ Restrepo, Juan Pablo. La Iglesia y el Estado en Colombia, Banco Popular, Tomo 1, Bogotá: 1987, pp.167-68

${ }^{5}$ Restrepo, José Manuel. Historia de Colombia. pp.27-593 del tomo $1^{\circ}$
} 
Esta distribución fue modificada en 1541 por el Emperador Carlos V que dispuso, el 3 de febrero, que los productos de los diezmos se dividieran en cuatro partes, de las cuales una se aplicaba al obispo, otra al cabildo eclesiástico, y de las dos restantes se deducirían dos novenas partes para la Real Hacienda, tres para las fabricas de la iglesias y para los hospitales, y las cuatro restantes se repartirían entre los curas y los sacristanes. ${ }^{6}$

La distribución de los diezmos se conservó así hasta comienzos del siglo XIX, después por concesiones de la Santa Sede, el Rey solicitó percibir un noveno más de la masa total de los diezmos al fisco, sin perjuicio de los otros dos que siguió exigiendo. Este sistema de distribución continuo así hasta llegar la república.

Después de la independencia, el congreso de Cúcuta el 14 de octubre de 1821, designó, que hasta que se celebrase un concordato, con la silla apostólica, se vigilaran las leyes que regían en materia de diezmos.

Para los casos estudiados, tanto para la Nueva Granada como para el Ecuador, los diezmos se repartían una tercera parte para el estado y dos terceras partes para la iglesia. Convirtiéndose el diezmo en un ingreso permanente para el financiamiento del presupuesto del estado.

Se utilizaba como mecanismo de cobro la acción directa de la iglesia, a través de la autoridad pública y, por medio del remate de diezmos. Este último fue él más utilizado para facilitar la recolección y los rematistas que obtenían los derechos de recolección en

\footnotetext{
${ }^{6}$ Ibíd., p. 593
} 
una zona podían vender sus derechos a otras personas. Así se creaba todo un sistema de rematistas y recolectores. $^{7}$

Los sitios donde se recolectaban los diezmos fueron las diferentes diócesis de cada estado; Nueva Granada, se recolectabá en el Arzobispado de Bogotá, los obispados de Popayán, Cartagena y Santa Marta; y en Ecuador en las diócesis de Quito, Cuenca y Guayaquil, hacia estos mismos sitios se redistribuía los diezmos que le correspondían a la iglesia.

La distribución y administración de los diezmos, como la conveniencia de seguir cobrando este impuesto, causaron varios conflictos en ambos estados. En la Nueva Granada, hasta mediados del siglo XIX, no se registró un aumento considerable en la contribución del diezmo. Fue a partir de 1850, que el producto de esta contribución tuvo alzas importantes y con el surgimiento de los grupos económicos emergentes y su adhesión a las ideologías liberales, se planteo suprimir el diezmo porque representaba un obstáculo para el desarrollo de la agricultura.

"el diezmo católico es el primer obstáculo que impide sus progresos (de la agricultura y retarda su prosperidad) ...debe, pues abolirse para siempre tan injusto e insoportable tributo...". 8

En 1851 se dictó la ley que abolía el diezmo "se faculta a las provincias para eliminar las contribuciones de diezmos, primicias y derechos de estola. Así mismo se les da

\footnotetext{
7 Ver para Colombia Jaime Jaramillo Uribe. "La economía del Virreynato (1740-1810)", En: Historia económica de Colombia., José Antonio Ocampo (compilador), Biblioteca Familiar Presidencia de la República, Santafe de Bogotá: 1997, pp. 96-98 y para Ecuador Gonzalo Ortíz Crespo, Op. Cit, p. 258
} 
libertad a las cámaras provinciales para que reemplacen estos tributos y la mayor parte los cambian por una contribución directa asignándoles renta fija a los curas". 9 Medidas económicas que afectaban a la iglesia, pero que se llevaron a cabo; pues se necesitaba dinamizar la economía y por lo tanto lograr el progreso y desarrollo de la agricultura que les permitiera vincularse con la economía mundial.

Ecuador, el 18 de octubre de 1833 se expidió la primera ley ecuatoriana sobre diezmos. El estado se reservó para sí el tercio de la renta, el sobrante se dividía por tres: el primer tercio correspondía al obispo, sin otros descuentos que los del seminario y gastos; el segundo sumaba la renta capitular, es decir, ayuda que recibían el cabildo catedralicio con los mismos descuentos; y el tercero se distribuía en siete partidas como se había acostumbrado con los siete novenos beneficiados. ${ }^{10}$

El artículo $9^{\circ}$ de la citada ley señala como debía procederse a la recaudación (concluidos los remates de diezmos, los tesoreros departamentales, que continuaron siendo miembros de las juntas de jurisdicción unida, procederán a hacer la suma de la total importancia de las partidas y con la asistencia de los contadores de diezmo, deducirán el tercio correspondiente al estado, nombrándoles partidos y rematadores que libremente

\footnotetext{
${ }^{8}$ Martha Helena López R. y Patricio Pinto Q. La Iglesia católica y el estado en Colombia. Tesis, Facultad de Ciencias Jurídicas y socioeconómicas, Pontificia Universidad Javeriana, Bogotá: 1991, pp. 210-211 y en Villegas, op.cit. p.45.

${ }^{9}$ Villegas, op. Cit., p. 45

${ }^{10}$ Enrique Viniera. Supresión del diezmo impacto del cobro de tres por mil predios rústicos. Gobierno del Excmo Antonio Flores Jijón. Tesis, Facultad de Economía Pontificia Universidad Católica del Ecuador, Quito: 1995 , pp. 39-40
} 
escojan: los que hayan sido designados pertenecerán al fisco, y afianzaran a satisfacción de los tesoreros). ${ }^{11}$

Este mecanismo de cobro se prestó a abusos por parte de la autoridad civil:

Pese a que el fin de la ley era independizar la recaudación de la porción fiscal, de la que quedaba por la iglesia, el ramo de diezmos estaba sujeto íntegramente a remate; y del producto deducía el estado "el tercio" de la forma conveniente a sus intereses económicos, el fisco tenía decisivo interés de que la renta produjese lo más posible por obvios motivos fiscales; y los rematadores apelaban a cualquier genero de extorsión para la recaudación especialmente cuando se trataba de sencillas personas del campo. Quizá esta es una razón por la que el estado no se atreve por lo general a hablar de abusos de la iglesia en cuanto al diezmo de manera consistente, sino de extorsiones de los recaudadores y diezmeros. ${ }^{12}$

El cobro y contribución del diezmo se conservo así hasta los años 50. A partir de 1856 la distribución del diezmo se modificó de modo favorable para el estado. En los siguientes años se asignó el 50\%, esta era la tendencia general, excepto para el caso de Guayaquil $^{13}$.

En Guayaquil hasta finales de la década del 50, el monto del diezmo no subió mucho:

.....a partir de 1857 se experimenta un alza vertiginosa pues se eleva de 137.617 pesos, en 1853 , a 250.384 pesos, y se duplica para fines de la década del ochenta, en que alcanza la suma total de 525.970 pesos. Desde entonces, pasa a jugar un papel de fundamental importancia para el

\footnotetext{
${ }^{11}$ Ibidem., pp. 40

${ }^{12}$ Ibíd., pp. 41-42
} 
erario nacional, puesto que en varios años llega a representar casi un 40 por ciento de dichos ingresos. $^{14}$

La elevación del diezmo, que se experimentó en Guayaquil, se dio gracias a la producción y exportación del cacao. Convirtiéndose Guayaquil, en el lugar donde se concentró la mayor cantidad de dinero recogido por los diezmos.

El aumento del diezmo en Guayaquil, conduciría a dos conflictos importantes como señala Enrique Ayala.

\footnotetext{
“... uno era la fusión de la masa decimal, es decir la centralización de lo percibido por concepto de diezmos para redistribuirlos entre las tres diócesis existentes en el país... ...En segundo lugar, otro de los grandes conflictos fue el referente a los porcentajes de diezmos con que se quedaba el estado... ". 15
}

\section{Conflictos que se agudizarían en la década de los setenta.}

Hacia 1875 los terratenientes costeños emprenden una campaña pública para sustituir el diezmo, a través de la Sociedad de Agricultores fundada por ellos, propuesta que fue apoyada por otros sectores del país, como los terratenientes de provincia de la Sierra y los agricultores medios ${ }^{16}$. Como el diezmo fue un impuesto sobre la producción agrícola, impactaba especialmente a los productos que Ecuador estaba exportando en grandes cantidades al mercado mundial, como fue el caso del cacao; siendo los más

\footnotetext{
${ }^{13}$ Fuente Alba, op. Cit., pp. 56-57

${ }^{14}$ Ibíd., pp. 56-57

${ }^{15}$ Ayala pp. 97-98. Artículo de la Nueva Historia del Ecuador
} 
afectados los terratenientes costeños, por lo tanto de ellos nace la iniciativa de sustituir el diezmo.

El momento culminante en la discusión sobre la supresión de los diezmos se dió en la constituyente de 1878, en la cual no se llegó a ninguna discusión firme; en la convención de 1884, donde se volvió a discutir este asunto, se decidió mantener el diezmo o sustituirlo por el "tres por mil", y se encargo de este negocio al diplomático Antonio Flores, que era uno de los mas convencidos de esta tesis y, en 1889 bajo la presidencia de Flores a pesar de todas las oposiciones de parte del clero, se suscribió un convenio adicional al concordato, a través del cual se realizo la sustitución. ${ }^{17}$

Recopilando, la contribución del diezmo durante el siglo XIX, en ambos países, estuvo marcada por un bajo rendimiento y la extinción gradual del diezmo sobre algunos productos nuevos. Pero después de los años 50 se da un alza importante en la contribución de este impuesto, por la elevada elaboración de productos como el cacao en el Ecuador y convirtiendose en un obstáculo para el desarrollo de la agricultura en la Nueva Granada. Por lo tanto la contribución del diezmo se convirtió en un freno para el desarrollo y progreso de los cultivos, situación ante la cual ambos estados buscaron soluciones, que generaron la oposición de la iglesia.

La Nueva Granada plantea la supresión del diezmo como parte de las medidas liberales de mediados de siglo, que exigen eliminar todas las trabas que impedían el desarrollo y el progreso. Mientras en Ecuador, a partir de 1875 los terratenientes costeños inician su campaña contra la supresión del diezmo, que se logra consolidar en 1889 bajo la

\footnotetext{
${ }^{16}$ Ayala, Enrique. Lucha política y origen de los partidos en Ecuador, Quito: Coedición Corporación Editora Nacional y el TEHIS Taller de Estudios Históricos, Cuarta Edición 1988. pp. 220-221
} 
Presidencia del Dr. Antonio Flores Jijón, también con el objetivo de lograr el progreso y desarrollo de cultivos que los vincularan al mercado mundial.

${ }^{17}$ Ibíd. pp. 222-225 